\title{
Muscle Activation in Older Females after a Community-Based Resistance Training Program: A Pilot Study
}

\author{
Majid Mufaqam Syed-Abdul ${ }^{1,2}$ and Stephen D. Ball ${ }^{1,2, *}$ \\ 1 Department of Nutrition and Exercise Physiology, University of Missouri, Columbia, MO 65211, USA; \\ ms9rf@mail.missouri.edu \\ 2 MU-Extension, University of Missouri, Columbia, MO 65211, USA \\ * Correspondence: ballsd@missouri.edu; Tel.: +1-573-882-2334
}

check for updates

Citation: Syed-Abdul, M.M.; Ball, S.D. Muscle Activation in Older Females after a Community-Based Resistance Training Program: A Pilot Study. Reports 2021, 4, 38. https://doi.org/10.3390/ reports 4040038

Academic Editor: Cristoforo Comi

Received: 13 September 2021

Accepted: 13 October 2021

Published: 18 October 2021

Publisher's Note: MDPI stays neutral with regard to jurisdictional claims in published maps and institutional affiliations.

Copyright: (C) 2021 by the authors. Licensee MDPI, Basel, Switzerland. This article is an open access article distributed under the terms and conditions of the Creative Commons Attribution (CC BY) license (https:/ / creativecommons.org/licenses/by/ $4.0 /)$.

\begin{abstract}
Many randomized controlled trials utilizing resistance training have shown improvements in muscle activation in older adults. However, these programs lack applicability to communitydwelling older adults due to several challenges. Therefore, the purpose of this study was to test the effects of an eight-week community-based resistance training program on muscle activation in older adults. Eight females (age: $61 \pm 4$ years, body mass index (BMI): $31.7 \pm 5.7 \mathrm{~kg} / \mathrm{m}^{2}$ ) were enrolled in the study. The surface electromyography (sEMG) activity was evaluated before and after training for three muscles (biceps brachii, upper trapezius, and rectus femoris). Additional weight load tests were performed to measure muscle activation in response to the added resistance. After eight weeks of training, no changes were observed in muscle activation for biceps brachii and upper trapezius but was decreased for rectus femoris $(p=0.04)$. Furthermore, in response to weight loads, biceps brachii and upper trapezius improved muscle activation after training. In summary, eight weeks of community-based resistance training program non-significantly improved the activation of upper-body muscles in older adults.
\end{abstract}

Keywords: Stay Strong Stay Healthy; strength training; elderly; exercise; muscle

\section{Introduction}

Aging causes neuromuscular deteriorations due to reduced muscle activation and the selective atrophy of fast-twitch muscle fibers [1,2]. These declines in normal anatomical and physiological changes result in reduced muscle strength, which eventually increases the risk of fall, reduces mobility, increases the inability to perform day-to-day tasks, and reduces the accessibility of a social life in older adults [3,4]. Exercise regimens for older adults, including strength-based exercises, induce muscle activation [5]. This has been well established through randomized controlled studies in older adults that have reported beneficial effects of resistance training on muscle function, balance, and delayed neuromuscular fatigue [6-10]. The primary mechanisms through which these benefits were achieved were due to increased muscle activation with resistance training. Unfortunately, most of these studies lack applicability to community-dwelling older adults, because they were conducted in controlled laboratory settings (i.e., a setting in which participants perform tasks strictly in a facility that have standardized equipment or devices under the researcher's supervision) and not in real-world settings such as senior centers or YMCAs. To date, no study has investigated the effects of a community-based resistance training program for older adults on muscle activation, assessed by electromyographic (EMG) analysis. One evidence-based strength-training program for older adults that holds promise is the University of Missouri's Stay Strong Stay Healthy (SSSH) program [11-14]. Delivered in senior centers, YMCAs, nutrition centers, churches, and schools, the SSSH program has reached over 15,000 participants in five states over 12 years. SSSH research supports its efficacy as a fall reduction program, but little is known about how the SSSH program affects muscle activation. Therefore, the purpose of this study was to test the effects of an eight-week 
resistance training program on muscle activation in SSSH participants. The data presented here are pilot data from eight participants.

\section{Methods}

Eight female participants (age: $61 \pm 4$ years, BMI: $31.7 \pm 5.7 \mathrm{~kg} / \mathrm{m}^{2}$ ) attending the University of Missouri Extension's Stay Strong Stay Healthy (SSSH) program were recruited prior to the start of their training. Participants in this study are a cohort of a larger group (NCT02677363) who also went under surface EMG (sEMG) testing. The results presented here are only related to these eight participants. Details about the SSSH program have been described elsewhere [11-17]. Participants were informed about the study and written consent was obtained. The study was approved by the Health Science Institutional Review Board, University of Missouri's IRB (\#2003712), and was registered on ClinicalTrials.gov (NCT02677363).

\subsection{Inclusion and Exclusion Criteria}

Participants were required to be enrolled in the Stay Strong Stay Healthy program at the University of Missouri campus; all completed the required physical activity readiness questionnaire (PAR-Q, Canadian Society for Exercise Physiology, Ottawa, ON, Canada) [18]. If the participants were found to be physically limited based on their responses, a physician's authorization was required. Of the 20 participants in the original study [17], only 8 participants decided to participate in EMG studies due to time commitment issues.

\subsection{Study Design}

Participants' anthropometric measurements were performed after consenting and were scheduled for body composition (via dual X-ray absorptiometry, DEXA, version 13.5.2, Hologic A, Marlborough, MA, USA) and sEMG analysis, which were conducted within one week before the start of the program. Follow-up DEXA and sEMG analyses were performed within one week after the program. Participants performed exercises targeting both the lower-body and the upper-body muscles for one hour twice weekly for eight weeks [11-17].

\subsection{Exercise Training}

As indicated previously [17], participants were required to complete 16 sessions of incremental RT over eight weeks. Exercises performed by the participants are presented in Table 1. Participants started with one set of five repetitions without weights and progressed to two sets of ten repetitions with weights (Table 2). Participants completed two sessions per week for eight weeks, and each session lasted for 45 to $60 \mathrm{~min}$ [11-17]. The hand and leg weights used during these eight weeks have been described elsewhere [17].

Table 1. Exercises performed during the program.

\begin{tabular}{lll}
\hline \multicolumn{1}{c}{ Upper-Body Exercises } & \multicolumn{1}{c}{ Lower-Body Exercises } \\
\hline - Bicep curl & - Standing leg curl \\
- Overhead press & Seated row & Knee extension \\
- Wide-leg squat & - Toe stand \\
\hline
\end{tabular}

\subsection{The sEMG Protocol}

The sEMG analysis was performed using the MyoTrac Infiniti System (T9800, Montreal, QC, Canada), MyoTrac Infiniti Encoder (SA9800, Montreal, QC, Canada), and Uni-Gel Single Electrodes (T3425, Thought Technology Ltd., Montreal, QC, Canada) on biceps brachii, upper trapezius, and rectus femoris. The analysis was performed using Biograph Infinity software (Thought Technology Ltd., Montreal, QC, Canada). The selection of muscles was based on the types of exercises performed and comfortability of the participants, 
i.e., the quadriceps (rectus femoris) were deemed to primarily be affected by most of the lower-body exercises (wide-leg squat, standing leg curl, and knee extensions). The biceps brachii and upper trapezius were selected for evaluating upper-body exercises (biceps curl and overhead press) considering their importance in day-to-day activity.

Table 2. Progression of weights used during eight weeks (16 sessions) for each exercise.

\begin{tabular}{cccc}
\hline Exercise Class \# & Sets of Reps & Weights & Single-Leg Exercises \\
\hline 1 & 1 set of 5 repetitions $(1 \times 5)$ & No weights & Alternate legs each repetition \\
2 & $2 \times 5$ & No weights $, \mathrm{R}, \mathrm{L}, \mathrm{R}, \mathrm{L}, \mathrm{R}, \mathrm{L}, \mathrm{R}, \mathrm{L})$ \\
3 & $2 \times 6$ & No weights & Alternate legs each rep \\
4 & $2 \times 6$ & Alternate legs each rep \\
5 & $2 \times 8$ & With weights & Alternate legs each rep \\
6 & $2 \times 10$ & With weights & Alternate legs each rep \\
7 & $2 \times 10$ & With weights & Alternate legs each rep \\
8 & $2 \times 10$ & With weights & Alternate legs each rep \\
9 & $2 \times 10$ & With weights & $(1 \times 10$ R; $1 \times 10$ L, repeat $)$ \\
10 & $2 \times 10$ & With weights & Alternate legs each set \\
11 & $2 \times 10$ & With weights & Alternate legs each set \\
12 & $2 \times 10$ & With weights & No alternating $(2 \times 10 \mathrm{R} ; 2 \times 10 \mathrm{~L})$ \\
13 & $2 \times 10$ & $1-2$ adaptations with weights & No alternating \\
15 & $2 \times 10$ & Same adaptations with weights & No alternating \\
16 & $2 \times 10$ & $1-2$ new adaptations with weights & No alternating \\
& & Same adaptations with weights & No alternating \\
\hline
\end{tabular}

Abbreviations: $\mathrm{R}=$ Right; $\mathrm{L}=$ left.

Pre-test procedures: Tests were performed on the non-dominant hand and leg. The test areas were cleaned using an alcohol swab in a circular motion from inside out until redness appeared. This area was cleaned with a cotton ball prior to placing an electrode. Electrodes were placed just distal of the origin (positive) and on the gaster (negative). A neutral electrode was placed at least $10 \mathrm{~cm}$ away from either electrode, closer to the trunk of the body.

Testing: No measurements were performed immediately after the exercise sessions. The tests were performed in response to selected exercises (with and without weights) for each muscle. For the biceps brachii, participants were asked to perform one set of three repetitions of bicep curl without weights $(0 \mathrm{lb}$.), with three pounds $(3 \mathrm{lb}$.), and with five pounds $(5 \mathrm{lb}$.). For the upper trapezius muscle, the participant performed one set of three repetitions of shoulder press with $0 \mathrm{lb}$. and $3 \mathrm{lb}$. added. The $5 \mathrm{lb}$. weights were not added because some participants were unable to perform the task correctly with $5 \mathrm{lb}$. Lastly, for the rectus femoris muscle, participants performed one set of three repetitions of knee extensions with no weights. No weights were added for knee extension exercises because not all participants were able to perform knee extensions with $3 \mathrm{lb}$. and $5 \mathrm{lb}$.

\subsection{Statistical Analysis}

One subject dropped out of the study; therefore, analyses were performed for seven participants. Two-factor analysis of variance (ANOVA) was performed using IBM SPSS Software (IBM Corp, Armonk, NY, USA) to test the difference between pre- and postanalysis for the biceps brachii and upper trapezius muscles. A paired sample t-test was performed to compare pre- and post-analysis results for the rectus femoris.

\section{Results}

As shown in Table 3, subjects lost body weight $(p<0.001)$, which also led to a reduction in their BMI $(p=0.01)$. Interestingly, this reduction in body weight was observed without any significant changes in both absolute lean mass and percent lean mass. 
Table 3. Participant characteristics and body composition.

\begin{tabular}{|c|c|c|c|c|c|c|c|}
\hline \multirow{2}{*}{$\begin{array}{c}\text { Anthropometrics }(\mathbf{n}=\mathbf{7}) \\
\text { Age (years) }\end{array}$} & \multicolumn{3}{|c|}{ Baseline $^{a}$} & \multicolumn{3}{|c|}{ Change } & \multirow[t]{2}{*}{$p$-Value } \\
\hline & 61.1 & \pm & 1.5 & & & & \\
\hline Height (meters) & 1.66 & \pm & 0.03 & & & & \\
\hline Weight $(\mathrm{kg})$ & 83.5 & \pm & 6.6 & -1.8 & \pm & 0.5 & 0.008 \\
\hline $\begin{array}{l}\text { Body mass index }\left(\mathrm{kg} / \mathrm{m}^{2}\right) \\
\text { Body fat } b\end{array}$ & \multicolumn{6}{|c|}{ Body fat $b$} & 0.013 \\
\hline Total body fat (kg) & 33.9 & \pm & 3.6 & -0.81 & \pm & 0.36 & 0.063 \\
\hline Total body fat (\%) & 40.2 & \pm & 1.5 & -0.09 & \pm & 0.04 & 0.075 \\
\hline \multicolumn{8}{|l|}{ Body lean mass ${ }^{c}$} \\
\hline Total lean (kg) & 46.8 & \pm & 2.6 & -0.46 & \pm & 0.20 & 0.058 \\
\hline Total lean (\%) & 57.0 & \pm & 1.4 & -0.60 & \pm & 0.29 & 0.310 \\
\hline Trunk lean (\%) & 29.2 & \pm & 1.0 & -0.17 & \pm & 0.38 & 0.757 \\
\hline Left arm lean (\%) & 2.4 & \pm & 0.1 & -0.01 & \pm & 0.03 & 0.961 \\
\hline Right arm lean (\%) & 2.8 & \pm & 0.1 & -0.08 & \pm & 0.05 & 0.184 \\
\hline Left leg lean $(\%)$ & 9.5 & \pm & 0.2 & -0.17 & \pm & 0.19 & 0.360 \\
\hline Right leg lean (\%) & 9.7 & \pm & 0.3 & -0.07 & \pm & 0.20 & 0.821 \\
\hline
\end{tabular}

${ }^{a}$ Data are reported as the mean \pm SE. ${ }^{b}$ Percentage calculations for body fat: total fat $\%$ - [total fat mass $(\mathrm{kg}) /$ total body weight $\left.(\mathrm{kg})\right] .{ }^{\mathrm{c}}$ Calculation shown in $\mathrm{b}$ was utilized to calculate the total lean mass percentage.

As shown in Figure 1, before training, the biceps brachii's RMS $(\mu \mathrm{V})$ did not change in response to a $3 \mathrm{lb}$. load (change of $-1.5 \%$ ); however, with a $5 \mathrm{lb}$. weight load, RMS increased by $27 \%$ compared to $0 \mathrm{lb}$. weight load $(p=0.07)$ and $29 \%$ compared to $3 \mathrm{lb}$. weight load $(p=0.002)$. After eight weeks of resistance training, the RMS value with $0 \mathrm{lb}$. was $10 \%$ lower than the pre-training value. With a $3 \mathrm{lb}$. weight load, RMS was increased by $19 \%$ compared to the $0 \mathrm{lb}$. weight load and continued to increase by $31 \%$ compared to the $0 \mathrm{lb}$. weight load ( $p=0.07$, increase compared to $3 \mathrm{lb}$. weight load was $10 \%$ ). When a two-factor ANOVA was performed, a significant difference was observed within the group ( $p=0.022)$, but not between groups $(p=0.625)$. Similarly, as shown in Figure 2 , before training, upper trapezius' RMS did not increase significantly with the $3 \mathrm{lb}$. weight load (increase of $6 \%$ ). After completion of the training, the RMS value with $0 \mathrm{lb}$. weight load was not different $(0 \%)$, whereas the $3 \mathrm{lb}$. weight load tended to increase RMS by 20\% $(p=0.10)$. When a two-factor ANOVA was performed, a significant difference was observed within the group $(p=0.023)$, but not between groups $(p=0.492)$. Lastly, as shown in Figure 3, a significantly lower RMS value (decreased by $56 \%$ ) was recorded for the rectus femoris after completion of the program $(p=0.04)$.

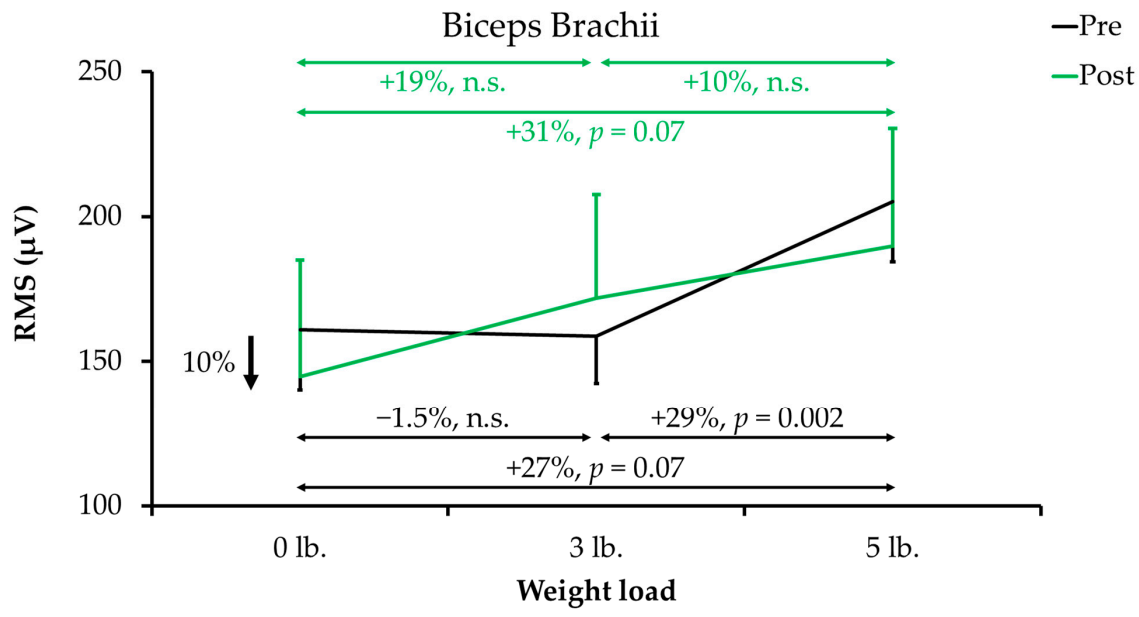

Figure 1. Surface electromyography (sEMG) activity of the biceps brachii before and after the resistance training program. Data are reported as the mean \pm SE. The black line represents sEMG activity before the resistance training program, and the green line represents sEMG activity after the resistance training program. Abbreviations: n.s., non-significant; RMS, root mean square. 


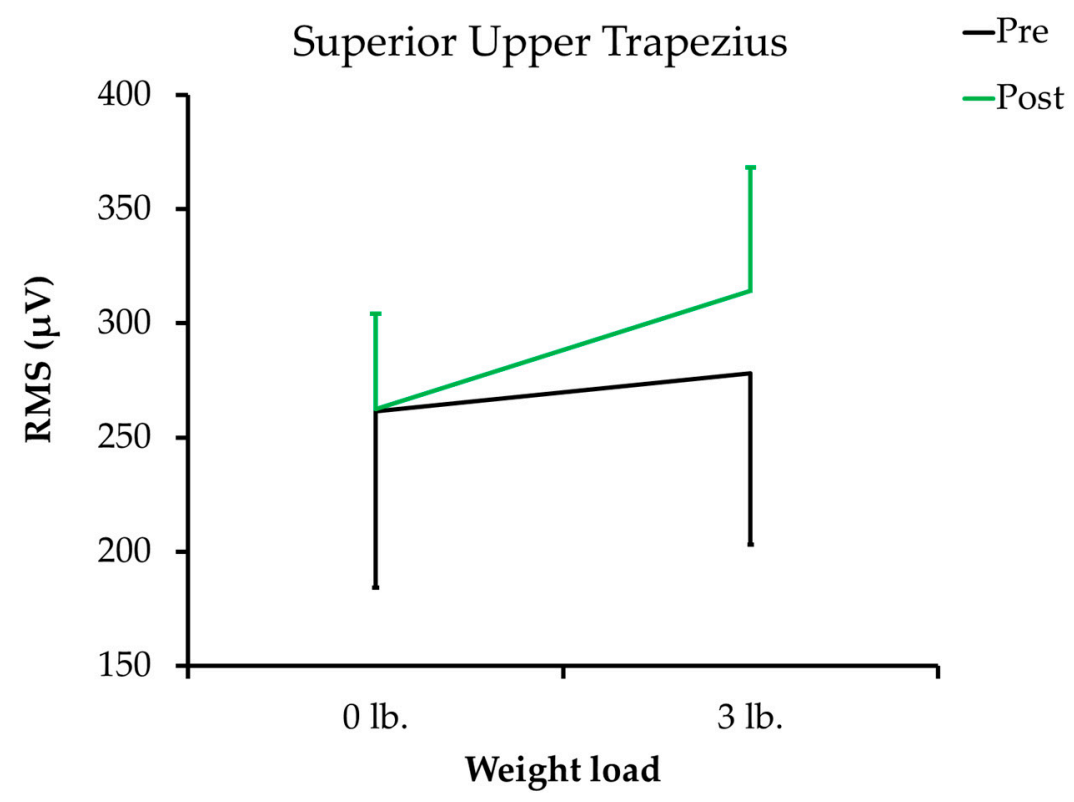

Figure 2. Surface electromyography (sEMG) activity of the superior upper trapezius before and after the resistance training program. Data are reported as the mean \pm SE. The black line represents sEMG activity before the resistance training program, and the green line represents sEMG activity after the resistance training program. Abbreviations: n.s., non-significant; RMS, root mean square.

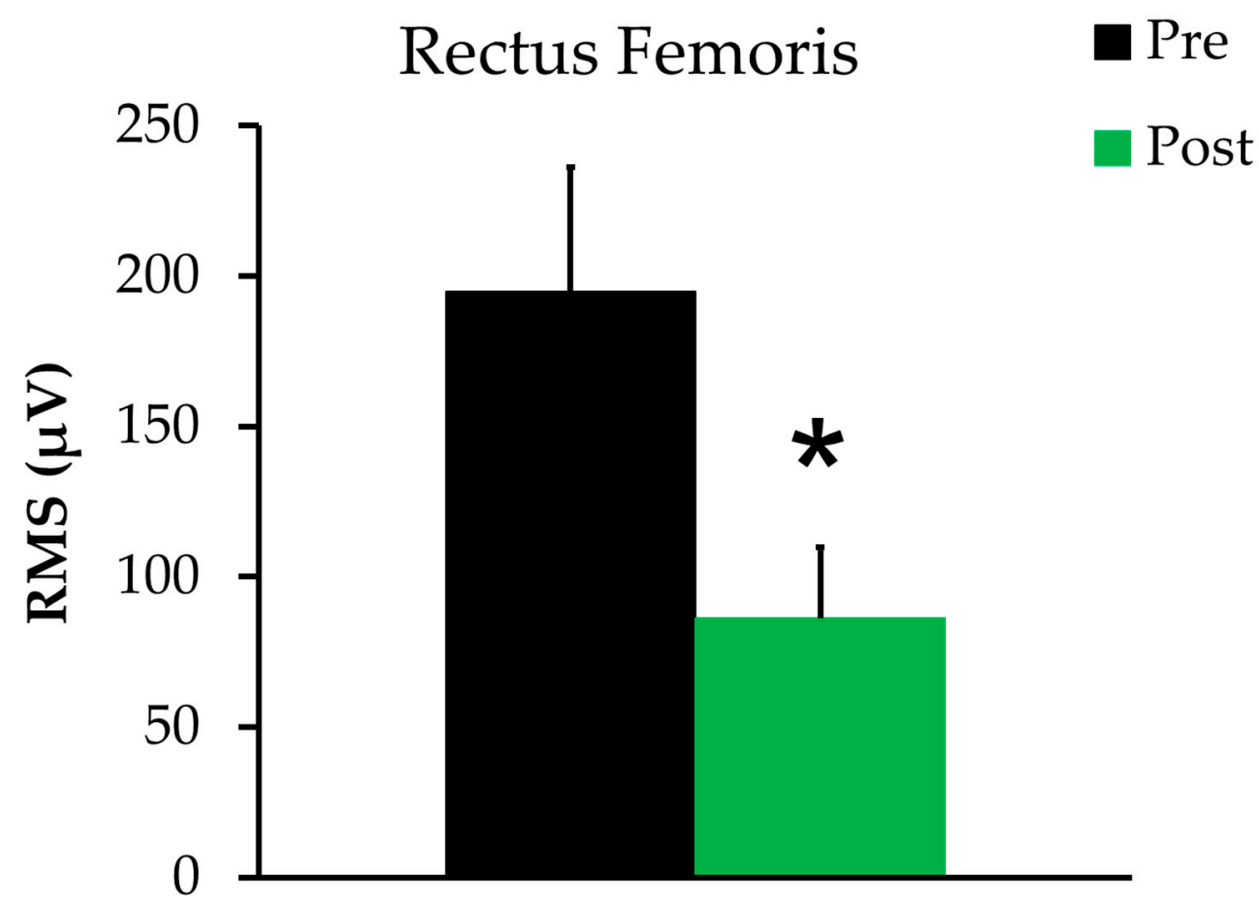

$0 \mathrm{lb}$.

\section{Weight load}

Figure 3. Surface electromyography (sEMG) activity of the rectus femoris before and after the resistance training program. Data are reported as the mean \pm SE. The black bar represents sEMG activity before the resistance training program, and the green bar represents sEMG activity after the resistance training program. ${ }^{*} p=0.04$. 


\section{Discussion}

The main purpose of this study was to test the effects of a community-based resistance training program (SSSH) on muscle activation in older adults. The benefits of resistance training have been demonstrated previously [17]; however, no study has measured muscle activation in a community-based resistance training program until now. Eight weeks of the SSSH program maintained EMG activity for two of the three muscles tested (biceps brachii and upper trapezius), suggesting the program non-significantly improved or maintained muscle activation levels in older adults.

Regarding weight load in biceps brachii, a non-significant decrease in EMG activity (by $1.5 \%$ ) observed with $3 \mathrm{lb}$. weight load before training has previously been observed in young adults [19]. Warren et al. [19] suggest that this decrease in EMG is due to a decrease in the activation of fast-motor units with a simultaneous increase in the activation of slow-motor units. The participants in that study were healthy young adults (26.7 \pm 4.8 years), although their previous training status was not mentioned. A massive increase observed in EMG activity with a $5 \mathrm{lb}$. weight load in the present study suggests that a greater weight load was required before training to recruit more fast-motor units [20]. Interestingly, after training, a progressive linear increase in EMG activity with $3 \mathrm{lb}$. and $5 \mathrm{lb}$. workloads suggests increased responsiveness in muscle recruitment. Additionally, previous studies have shown better muscle activation and recruitment in resistance-trained individuals compared to untrained individuals [21]. Another study conducted by Fiebert et al. [22] has also reported a progressive increase in EMG activity with workload in healthy adult men and women [22]. However, previous studies reported these benefits in young adults, whereas the present study was focused on community-dwelling older adults and reported similar benefits. These data suggest that for biceps brachii, the resistance provided during the SSSH program was sufficient to maintain (or non-significantly improve) muscle activation levels. Weight load data support the notion that resistance training can also improve the muscle efficiency (recruitment) of biceps brachii in response to weight load in older adults.

With regard to weight load tests conducted for the upper trapezius muscle, the lack of increase in EMG activity observed before training in response to a $3 \mathrm{lb}$. weight is similar to the response observed for biceps brachii muscle and can be attributed to the fact that the participants were untrained [21]. After training, a drastic increase in EMG activity $(20 \%, p=0.10)$, in response to $3 \mathrm{lb}$., is consistent with a previous study conducted by Lane et al. [23] in fire-fighters, in which trapezius muscle EMG activity increased with the workload. Similar to outcomes observed for biceps brachii muscle, these data suggest that resistance training provided in real-world settings can maintain (or non-significantly improve) upper trapezius muscle activation levels. Although the lack of significance in the current study can be attributed to a small size, EMG analysis can also be influenced during an overhead press exercise by the type of instructions, stability during the test, and training status [21,24-26]. However, in the present study, participants were clearly instructed on how to perform the exercise. Moreover, only a $3 \mathrm{lb}$. weight load was used during the test; the $5 \mathrm{lb}$. weight load was avoided because some participants were unable to stably perform the exercise using this weight. Therefore, we believe that the results observed in the current study are representative of the participant's actual muscle activation.

Furthermore, consistent with previous research conducted in a well-controlled laboratorybased environment, EMG activity was decreased in the rectus femoris muscle after eight weeks of training $[6,8-10,27]$. Although the muscle activation levels were deceased in the rectus femoris muscle, others have postulated two plausible explanations for this decrease. First, with training or continuous bouts of exercises, muscle recruitment switches more towards slow-motor units and less towards fast-motor units $[19,20]$. The participants in this study trained for eight weeks; therefore, their muscles may have shifted predominantly toward the recruitment of slow-motor units during the non-weight load tests [20]. Therefore, the rectus femoris' EMG activity was decreased by more than $50 \%$; these data suggest that the number of motor units required to perform a knee extension after training 
was reduced by half. Second, the eight weeks of exercise may not have been sufficient to observe increased muscle activation. In this study, we did not perform weight load tests for the rectus femoris muscle, which could have provided greater insights into the actual activation potency of the rectus femoris muscle. Furthermore, we did not report any changes in EMG activity for the other two muscle groups (biceps brachii and upper trapezius), which suggests that resistance training provided in a real-world setting may benefit specific muscle groups based on their location (upper body vs. lower body). However, the present study was not designed to test these differences; therefore, further investigation is needed in this area.

Lastly, some of the benefits of improved EMG activity include preventing falls and improving the day-to-day activity of older adults, leading to independence. The inability of muscles to activate appropriately may result in falls, which is why older adults with weaker muscles are at greater risk of falls $[3,28]$. Additionally, in the day-to-day activity of older adults, it is important that the muscles activate appropriately in response to specific weight loads. Before training, both upper muscles under investigation were misaligned with weight load, whereas, after training, activation observed for both upper muscles aligned in response to different weight loads, suggesting improved muscle activation. These findings implicate that the changes in EMG observed after eight weeks of the SSSH program are beyond muscular health in older adults.

\section{Conclusions}

In summary, eight weeks of community-based resistance training improved the EMG activity of upper-body muscles in older adults. The outcomes suggest that real-world community-based strength training programs such as SSSH can maintain muscle activation in older adults in eight weeks. Therefore, resistance training programs such as SSSH should be incorporated in communities, and older adults should be encouraged to participate in such programs. Participation in such programs can help to improve muscle activity in older adults and can help them remain active and independent longer.

Author Contributions: M.M.S.-A. designed the study, conducted the experiment, curated the data, performed the analysis, wrote the first draft, and revised the manuscript. S.D.B. designed the study, supervised the study, provided significant input in data analysis, and edited the manuscript. All authors have read and agreed to the published version of the manuscript.

Funding: The research received no external funding and the APC was funded by MU Extension, University of Missouri, Columbia, MO, USA, 65211.

Institutional Review Board Statement: The study was conducted according to the guidelines of the Declaration of Helsinki, and approved by the Institutional Review Board of the University of Missouri, Columbia (project number: 2003712, date of approval: 10/28/2015).

Informed Consent Statement: Informed consent was obtained from all subjects involved in the study.

Data Availability Statement: The data presented in this study are available on request from the corresponding author. The data are not publicly available because this was a preliminary study.

Conflicts of Interest: The authors declare no conflict of interest.

\section{References}

1. Yamada, H.; Okada, M.; Oda, T.; Nemoto, S.; Shiozaki, T.; Kizuka, T.; Kuno, S.; Masuda, T. Effects of aging on EMG variables during fatiguing isometric contractions. J. Hum. Ergol. 2000, 29, 7-14.

2. Cecílio, F.A.; Regalo, S.C.H.; Palinkas, M.; Issa, J.P.M.; Siéssere, S.; Hallak, J.E.C.; Machado-De-Sousa, J.P.; Semprini, M. Ageing and surface EMG activity patterns of masticatory muscles. J. Oral Rehabil. 2010, 37, 248-255. [CrossRef] [PubMed]

3. Moreland, J.D.; Richardson, J.A.; Goldsmith, C.H.; Clase, C.M. Muscle Weakness and Falls in Older Adults: A Systematic Review and Meta-Analysis. J. Am. Geriatr. Soc. 2004, 52, 1121-1129. [CrossRef] [PubMed]

4. McLean, R.R.; Shardell, M.D.; Alley, D.E.; Cawthon, P.M.; Fragala, M.S.; Harris, T.B.; Kenny, A.M.; Peters, K.W.; Ferrucci, L.; Guralnik, J.M.; et al. Criteria for Clinically Relevant Weakness and Low Lean Mass and Their Longitudinal Association with 
Incident Mobility Impairment and Mortality: The Foundation for the National Institutes of Health (FNIH) Sarcopenia Project. J. Gerontol. Ser. A 2014, 69, 576-583. [CrossRef]

5. Morse, C.I.; Thom, J.; Mian, O.; Birch, K.; Narici, M.V. Gastrocnemius specific force is increased in elderly males following a 12-month physical training programme. Graefe's Arch. Clin. Exp. Ophthalmol. 2006, 100, 563-570. [CrossRef] [PubMed]

6. Kobayashi, Y.; Ueyasu, Y.; Yamashita, Y.; Akagi, R. Effects of 4 Weeks of Explosive-type Strength Training for the Plantar Flexors on the Rate of Torque Development and Postural Stability in Elderly Individuals. Int. J. Sports Med. 2016, 37, 470-475. [CrossRef] [PubMed]

7. Reichert, T.; Bagatini, N.C.; Simmer, N.M.; Meinerz, A.P.; Barroso, B.M.; Prado, A.K.G.; Delevatti, R.; Costa, R.R.; Kanitz, A.C.; Kruel, L.F.M. Effects of Different Models of Water-Based Resistance Training on Muscular Function of Older Women. Res. $Q$. Exerc. Sport 2019, 90, 46-53. [CrossRef] [PubMed]

8. $\quad$ Emerson, N.S.; Stout, J.R.; Fukuda, D.H.; Robinson, E.H.; Iv; Scanlon, T.C.; Beyer, K.S.; Fragala, M.S.; Hoffman, J.R. Resistance training improves capacity to delay neuromuscular fatigue in older adults. Arch. Gerontol. Geriatr. 2015, 61, 27-32. [CrossRef] [PubMed]

9. Cadore, E.L.; Pinto, R.S.; Pinto, S.S.; Alberton, C.L.; Correa, C.S.; Tartaruga, M.P.; Silva, E.M.; Almeida, A.P.V.; Trindade, G.T.; Kruel, L.F.M. Effects of Strength, Endurance, and Concurrent Training on Aerobic Power and Dynamic Neuromuscular Economy in Elderly Men. J. Strength Cond. Res. 2011, 25, 758-766. [CrossRef] [PubMed]

10. Ploutz, L.L.; Tesch, P.A.; Biro, R.L.; Dudley, G.A. Effect of resistance training on muscle use during exercise. J. Appl. Physiol. 1994, 76, 1675-1681. [CrossRef]

11. Crowe, E.M.; Ball, S.D. Effectiveness of Advanced Stay Strong, Stay Healthy in Community Settings. Gerontol. Geriatr. Med. 2015, 1, 2333721415596462. [CrossRef]

12. Ball, S.; Gammon, R.; Kelly, P.J.; Cheng, A.-L.; Chertoff, K.; Kaume, L.; Abreu, E.L.; Brotto, M. Outcomes of Stay Strong, Stay Healthy in Community Settings. J. Aging Health 2013, 25, 1388-1397. [CrossRef] [PubMed]

13. Baker, B.S.; Weitzel, K.J.; Royse, L.; Miller, K.; Guess, T.M.; Ball, S.D.; Duren, D.L. Efficacy of an 8-Week Resistance Training Program in Older Adults: A Randomized Controlled Trial. J. Aging Phys. Act. 2021, 29, 121-129. [CrossRef]

14. Syed-Abdul, M.M.; Peterson, E.C.; Mills-Gray, S.L.; Parks, E.J.; Ball, S.D. Stay Strong, Stay Healthy. Med. Sci. Sports Exerc. 2016, 48, 125. [CrossRef]

15. Syed-Abdul, M.M.; Mills-Gray, S.L.; Parks, E.J.; Ball, S.D. Acute effects of incremental resistance training on muscle function in older adults. FASEB J. 2017, 31 (Suppl. 1), 1020.11.

16. Syed-Abdul, M.M.; McLellan, C.L.; Parks, E.J.; Ball, S.D. Effects of incremental resistance training program on quality of life in older adults. Int. J. Exerc. Sci. 2017, 11, 44.

17. Syed-Abdul, M.M.; McClellan, C.L.; Parks, E.J.; Ball, S.D. Effects of a resistance training community programme in older adults. Ageing Soc. 2021, 1-16. [CrossRef]

18. PHAC and CSEP, Physical Activity Readiness Questionnaire (PAR-Q). In Public Health Agency of Canada and the Canadian Society for Exercise Physiology. 2002. Available online: https:/ /geriatrictoolkit.missouri.edu/his/Par-Q.pdf (accessed on 14 October 2021).

19. Warren, G.L.; Hermann, K.M.; Ingalls, C.P.; Masselli, M.R.; Armstrong, R.B. Decreased EMG median frequency during a second bout of eccentric contractions. Med. Sci. Sports Exerc. 2000, 32, 820-829. [CrossRef] [PubMed]

20. Lee, S.S.M.; Miara, M.D.B.; Arnold, A.S.; Biewener, A.A.; Wakeling, J.M. Recruitment of faster motor units is associated with greater rates of fascicle strain and rapid changes in muscle force during locomotion. J. Exp. Biol. 2013, 216, 198-207. [CrossRef]

21. Syed-Abdul, M.M.; Soni, D.S.; Miller, W.M.; Johnson, R.J.; Barnes, J.T.; Pujol, T.J.; Wagganer, J.D. Traditional Versus Suspended Push-up Muscle Activation in Athletes and Sedentary Women. J. Strength Cond. Res. 2018, 32, 1816-1820. [CrossRef]

22. Fiebert, I.M.; Spielholz, N.I.; Applegate, E.; Fox, C.; Jaro, J.; Joel, L.; Raper, L. Comparison of EMG activity of medial and lateral hamstrings during isometric contractions at various cuff weight loads. Knee 2001, 8, 145-150. [CrossRef]

23. Lane, C.L.; Hardwick, D.; Janus, T.P.; Chen, H.; Lu, Y.; Mayer, J.M. Comparison of the firefighter candidate physical ability test to weight lifting exercises using electromyography. Work 2019, 62, 459-467. [CrossRef]

24. Daniels, R.J.; Cook, S.B. Effect of instructions on EMG during the bench press in trained and untrained males. Hum. Mov. Sci. 2017, 55, 182-188. [CrossRef] [PubMed]

25. Dicus, J.R.; Holmstrup, M.E.; Shuler, K.T.; Rice, T.T.; Raybuck, S.D.; Siddons, C.A. Stability of Resistance Training Implement alters EMG Activity during the Overhead Press. Int. J. Exerc. Sci. 2018, 11, 708-716. [PubMed]

26. Vigotsky, A.D.; Halperin, I.; Lehman, G.J.; Trajano, G.; Vieira, T.M. Interpreting Signal Amplitudes in Surface Electromyography Studies in Sport and Rehabilitation Sciences. Front. Physiol. 2018, 8, 985. [CrossRef] [PubMed]

27. Oliveira, A.D.S.C.; Gonçalves, M. EMG amplitude and frequency parameters of muscular activity: Effect of resistance training based on electromyographic fatigue threshold. J. Electromyogr. Kinesiol. 2009, 19, 295-303. [CrossRef]

28. Horlings, C.G.; Van Engelen, B.G.; Allum, J.H.; Bloem, B.R. A weak balance: The contribution of muscle weakness to postural instability and falls. Nat. Clin. Pract. Neurol. 2008, 4, 504-515. [CrossRef] [PubMed] 